\title{
Pharmacogenetic evaluation to assess breakthrough psychosis with aripiprazole long-acting injection: a case report
}

\author{
Seenae Eum ${ }^{1 \dagger}$, Mark E. Schneiderhan ${ }^{2 \dagger}$, Jacob T. Brown ${ }^{2}$, Adam M. Lee ${ }^{1}$ and Jeffrey R. Bishop ${ }^{3^{*}}$
}

\begin{abstract}
Background: Given the complex nature of symptom presentation and medication regimens, psychiatric clinics may benefit from additional tools to personalize treatments. Utilizing pharmacogenetic information may be helpful in assessing unique responses to therapy. We report herein a case of wearing-off phenomena during treatment with aripiprazole long-acting injectable (LAI) and a proof of concept strategy of how pharmacogenetic information may be used to assess possible genetic factors and also hypothesize potential mechanisms for further study.

Case presentation: A 51-year-old African American male with schizoaffective disorder was referred to a psychiatric clinic for medication management. After unsuccessful trials of multiple antipsychotics, oral aripiprazole was initiated (up to $30 \mathrm{mg} /$ day) and transitioned to aripiprazole LAl with symptom improvement. At a high dose of aripiprazole LAl (400 mg Q3wks), the patient experienced breakthrough symptoms approximately 3 days prior to his next injection. Various considerations were examined to explain his atypical dose requirements, including but not limited to pharmacogenetic influences. Pharmacogenetic testing ruled out genetic influences on drug metabolism but noted a -141C Del variant in the dopamine-D2 receptor (DRD2) gene associated in prior studies of poor-response to antipsychotics. At this time, a new formulation, aripiprazole lauroxil, was explored due to its availability in higher dose options. Transition to the new formulation (882 mg Q4wks) greatly improved and stabilized the patient's symptoms with no breakthrough psychosis. Comparable daily dose equivalents were achieved with two different formulations due to the Q3wks vs Q4wks dosing strategies, although the two agents have some differences in pharmacokinetic profiles.

Conclusions: We report a case of a patient experiencing wearing-off symptoms with aripiprazole LAI who benefited from switching to aripiprazole lauroxil. Pharmacogenetic testing revealed normal activity for relevant metabolism pathways but a DRD2 -141C variant that may influence brain D2 expression and antipsychotic responsiveness. The clinical utility of DRD2 information and what to do with genotyping results has not been previously addressed, despite availability on clinical test panels. Our case report suggests further investigations of altered dosing strategies and receptor genotype sensitivities to pharmacokinetic factors may be helpful in understanding symptom re-emergence observed in some patients taking LAl antipsychotics.
\end{abstract}

Keywords: Aripiprazole long-acting injectable, Wearing-off symptoms, DRD2, Clinical pharmacogenetic testing

\footnotetext{
* Correspondence: jrbishop@umn.edu

'Equal contributors

${ }^{3}$ College of Pharmacy, Department of Experimental and Clinical

Pharmacology and College of Medicine, Department of Psychiatry, University

of Minnesota, 308 Harvard St. S.E., Minneapolis, MN 55455, USA

Full list of author information is available at the end of the article
} 


\section{Background}

Approximately one-third of patients with schizophrenia treated with antipsychotics continue to experience persistent psychotic symptoms [1]. Moreover, given the complex nature of symptom presentation and medication regimens in patients with psychotic disorders, outpatient psychiatric clinics are in need of ways to improve patient care. Although there are no simple tests to determine if a patient will have a response or remission of schizophrenia symptoms with a selected antipsychotic agent and dose, pharmacogenetic information along with other clinical information may offer great potential to optimize pharmacotherapy and improve the overall quality of life in psychiatric patients.

Pharmacogenetics is the study of how genetic variations influence drug therapy and focuses on the variants associated with pharmacokinetics and pharmacodynamics of medications. Over 160 medications, including antipsychotics such as aripiprazole, list pharmacogenetic information in the product labeling to date [2]. Neuropsychiatric medications account for about one-third of those, including many commonly used antidepressant, antipsychotic, and antiepileptic medications [3]. While research in psychiatric pharmacogenetics has significantly increased over the past 20 years, clinical application is just beginning with many emerging questions of how, when, and if to use this information.

The pharmacogenetic biomarker most commonly included in the product labeling for many antipsychotic medications is the cytochrome P450 2D6 (CYP2D6) gene related to drug metabolism and pharmacokinetic properties of drugs such as aripiprazole, risperidone, perphenazine, iloperidone, and others $[2,4,5]$. Genes thought to impact pharmacodynamics of antipsychotics (e.g. dopamine-D2, serotonin-5HT2A receptors, etc.) are not included in product labeling, but are often included in many available genetic testing panels for psychotropic medications. While there are studies published highlighting the mechanistic consequences of some polymorphisms in these genes as well as associations with some clinical outcomes, the clinical utility of pharmacodynamic gene variants in guiding antipsychotic pharmacotherapy is not as clear as variants which influence pharmacokinetics. Variation in the dopamine-D2 receptor gene (DRD2) is one example of a pharmacodynamic gene that has been extensively investigated in relation to treatment outcomes, as it is a primary target for all currently available antipsychotic agents. Although there are conflicting results, metaanalyses highlight that the rs1799732 -141C Ins/Del 'deletion' polymorphism may be associated with decreased responsiveness to antipsychotic medications $[6,7]$. How to consider this information in the context of clinical care is unclear.
Aripiprazole (oral), one of the antipsychotic agents examined in the meta-analysis [6], was approved by the U.S. Food and Drug Administration (FDA) in late 2002 for the treatment of schizophrenia, and is a unique second generation antipsychotic with partial agonist activity at D2 and serotonin (5-hydroxytryptamine, 5-HT) 1A receptors, and antagonist activity at 5-HT2A receptors [8]. The first aripiprazole longacting injectable (LAI) formulation, Abilify Maintena ${ }^{\circ}$, was approved in early 2013 at the recommended dose of $400 \mathrm{mg}$ IM injection every 4 weeks [8]. Aripiprazole lauroxil (Aristada ${ }^{\circ}$ ) is a newer LAI aripiprazole formulation, which was FDA approved in October 2015 [8]. Aripiprazole lauroxil is an N-acyloxymethyl prodrug that undergoes a 2 -step bioconversion in the plasma from the lauroxil to an intermediate, $\mathrm{N}$ hydroxymethyl-aripiprazole via enzyme-mediated hydrolysis. The N-hydroxymethyl-aripiprazole then undergoes a hydrolysis reaction to aripiprazole [9]. Aripiprazole lauroxil is available at a dose of $441 \mathrm{mg}$ (deltoid or gluteal), $662 \mathrm{mg}$ and $882 \mathrm{mg}$ (only gluteal) corresponding to aripiprazole LAI $300 \mathrm{mg}, 450 \mathrm{mg}$ and $600 \mathrm{mg}$ (corresponding to oral aripiprazole $10 \mathrm{mg} /$ day, $15 \mathrm{mg} /$ day and $20 \mathrm{mg} /$ day), respectively [8]. While these two formulations are similar with respect to dosing/administration intervals, they are different with regards to their formulations which influence some of their pharmacokinetic parameters including $\mathrm{T}_{1 / 2}$ and $\mathrm{T}_{\max }$ [8]. The clinical implications of these differences in the context of altered drug metabolism or target receptor sensitivities are unclear.

The dosing strategies for LAI antipsychotics include relatively standardized conversions from oral formulations to recommended administration intervals. The injection intervals for LAIs depend on the specific agent (e.g. every 4 weeks for aripiprazole, haloperidol, and paliperidone; every 2 weeks for risperidone, etc.) and are based on extensive pharmacokinetic studies of patients as well as computer simulations [10]. Although not extensively reported in the literature, there are clinical reports of some patients requiring shorter dosing intervals or higher than approved doses of LAI antipsychotics with unclear reasons.

Here, we present a case of a patient with treatment-refractory schizoaffective disorder for whom pharmacogenetic testing was obtained in an attempt to explain his wearing-off symptoms with aripiprazole LAI $400 \mathrm{mg}$ every 3 weeks combined with daily oral aripiprazole. Although there have been anecdotal clinical reports of symptom breakthrough at the end of a LAI antipsychotic dosing cycle, no published studies or cases have previously reported this phenomena with aripiprazole LAI. This case discussion focuses on pharmacogenetic testing as a proof of concept 
strategy to hypothesize a mechanism and management strategy for these breakthrough phenomena with aripiprazole LAI.

\section{Case presentation}

$\mathrm{AB}$, a 51-year-old African American male [height $195.6 \mathrm{~cm}$, weight $141 \mathrm{~kg}$, body mass index $36.9 \mathrm{~kg} / \mathrm{m}^{2}$ ] with chart diagnoses of schizoaffective disorder, depressive type and post-traumatic stress disorder, was referred to a community mental health center in March of 2014 to address medication non-adherence and lack of medication effectiveness. AB's symptoms were first reported in 2006 and included depressed mood and persecutory auditory hallucinations with command hallucinations to either self-harm (e.g. insulin overdose) or stop his medications. His referral in 2014 included details of treatment and symptoms since 2008. The referral notes highlighted a complicated psychiatric history with approximately eight psychiatric hospitalizations over the previous five years, predominantly attributed to depressive episodes and suicide attempts. His other medical history includes uncontrolled type 2 diabetes with diabetic neuropathy, hypertension, asthma, obstructive sleep apnea, diverticulitis, chronic musculoskeletal pain, and chronic headaches. His medication list at the time of this report (February, 2017) is provided in Table 1.

Between 2008 and 2012, he was trialed on and off multiple antipsychotic agents including risperidone (titrated up to $6 \mathrm{mg} /$ day), haloperidol (titrated up to $15 \mathrm{mg} /$ day), quetiapine (titrated up to $800 \mathrm{mg} /$ day), and ziprasidone (titrated up to $200 \mathrm{mg} /$ day); all for a duration of at least 12 weeks without significant improvement. A trial of olanzapine (titrated up to $15 \mathrm{mg} /$ day) resulted in slightly improved psychotic symptoms; however, was ultimately discontinued due to worsening diabetes control. At this time, oral aripiprazole $5 \mathrm{mg} /$ day was started (April 2012).

Table 1 Patient's current medication list

\begin{tabular}{|c|c|c|c|}
\hline Indication & Medication & Dose & Route of Administration \\
\hline \multicolumn{4}{|l|}{ Mental Health } \\
\hline Schizoaffective disorder & Aripiprazole lauroxil & 882 mg once a month & $\mathrm{IM}$ \\
\hline Depression & Sertraline & 150 mg every morning & $\mathrm{PO}$ \\
\hline Insomnia & Zolpidem CR & $12.5 \mathrm{mg}$ at bedtime & $\mathrm{PO}$ \\
\hline Smoking cessation & Varenicline & $1 \mathrm{mg} \mathrm{BID}$ & $\mathrm{PO}$ \\
\hline \multicolumn{4}{|l|}{ Cardiovascular } \\
\hline \multirow[t]{4}{*}{ Hypertension } & Amlodipine & 10 mg once a day & $\mathrm{PO}$ \\
\hline & Atenolol & 50 mg once a day & $\mathrm{PO}$ \\
\hline & Losartan & 100 mg once a day & $\mathrm{PO}$ \\
\hline & Spironolactone & 100 mg once a day & $\mathrm{PO}$ \\
\hline Prevention of CV disease & Aspirin & 81 mg once a day & $\mathrm{PO}$ \\
\hline \multicolumn{4}{|l|}{ Type 2 DM } \\
\hline \multirow[t]{3}{*}{$\mathrm{DM}$} & Insulin glargine & 120 units BID & SC \\
\hline & Insulin aspart & As directed & SC \\
\hline & Metformin & 1000 mg BID & $\mathrm{PO}$ \\
\hline Diabetic neuropathy & Gabapentin & 1200 mg TID & $\mathrm{PO}$ \\
\hline \multicolumn{4}{|l|}{ Respiratory } \\
\hline \multirow[t]{3}{*}{ Asthma } & Ipratropium-albuterol & 18-103 mcg 2 puffs BID & Nasal \\
\hline & Albuterol nebulizer & As directed & Nasal \\
\hline & Budesonide-formoterol & $160-4.5$ mcg 2 puffs BID & Nasal \\
\hline \multirow[t]{2}{*}{ Congestion } & Fluticasone & 50 mcg 1 spray once a day & Nasal \\
\hline & Oxymetazoline & 0.05\% 1 spray every night & Nasal \\
\hline \multicolumn{4}{|l|}{ Pain } \\
\hline Pain & Tramadol & 100 mg TID PRN & $\mathrm{PO}$ \\
\hline \multicolumn{4}{|l|}{ Gastrointestinal } \\
\hline GERD & Omeprazole & 20 mg BID & $\mathrm{PO}$ \\
\hline
\end{tabular}


At the time of his referral (March, 2014), the patient was on oral aripiprazole $15 \mathrm{mg} /$ day, which was titrated up to $30 \mathrm{mg}$ /day through March 2015, and the patient reported improvement in auditory hallucinations, mood, and suicidal ideations. In March 2015, AB agreed to start long-acting injectable (LAI) aripiprazole with the goal to eventually discontinue the oral aripiprazole to provide a safeguard for non-adherence if the command hallucinations returned. Subsequently, aripiprazole LAI, $400 \mathrm{mg}$ intramuscularly (IM) was administered into the gluteal muscle every 4-weeks combined with oral aripiprazole $30 \mathrm{mg} /$ day. The plan was to reduce the aripiprazole oral dose to $15 \mathrm{mg} /$ day at 2-weeks post-injection. Eight weeks after initiating aripiprazole LAI, a marked improvement in psychiatric symptoms was noted. Over approximately 12-weeks, the oral aripiprazole supplementation was reduced to $5 \mathrm{mg} /$ day (June 2015); however, within 4-weeks of oral aripiprazole dose reduction to $5 \mathrm{mg} /$ day, his auditory hallucinations returned and worsened. The oral aripiprazole dose was then increased back to $7.5 \mathrm{mg} /$ day with a noticeable positive response. At a 2-week follow-up appointment after this dose increase (July 2015), auditory hallucinations were reported to be "not as bad" but worse 1-week prior to his aripiprazole injection, resulting in a modification of aripiprazole LAI frequency from $400 \mathrm{mg}$ IM every 4-weeks to every 3-weeks along with the $7.5 \mathrm{mg} /$ day oral aripiprazole. In October 2015, since he complained of worsening auditory hallucinations approximately 3 days prior to his next injection, oral aripiprazole $2 \mathrm{mg} /$ day as needed (up to 2 times/week) was added to his current regimen (aripiprazole LAI $400 \mathrm{mg}$ every 3 -week and oral aripiprazole $7.5 \mathrm{mg} /$ day) for this wearing-off symptoms.

The continuing need for oral aripiprazole and symptom breakthrough prior to his every 3-week aripiprazole injection prompted further inquiry as to which variables might be contributing to this pattern of response/nonresponse. Considerations included medications/substances interactions, pharmacokinetic characteristics, and administration techniques (i.e. site of administration, syringe length and gauge, etc.), all of which were ruled out as contributing factors. No significant drug/substance interactions were noted (Table 1). Since adherence was not in question with an LAI medication, serum drug concentrations were not ordered. Pharmacogenetic variables influencing drug metabolism were then considered, and a commercially available psychiatry-focused pharmacogenetic testing panel was ordered in October 2015 (Table 2).

Pharmacogenetic test results for drug-metabolizing enzymes cytochrome P450 2D6 (CYP2D6) and CYP3A4 did not explain the patient's need for high aripiprazole dose nor his breakthrough symptoms. However, the patient was found to carry a genetic variation in the dopamine receptor D2 gene (DRD2), $-141 \mathrm{C}$ Ins/Del polymorphism (rs1799732). This polymorphism has been linked to variation in striatal dopamine receptor density $[11,12]$ and reduced response to some antipsychotics [6], which is consistent with AB's reduced response to many antipsychotic agents.

With no clear pharmacogenetic influence on drug metabolism, yet a documented need for higher doses of aripiprazole, additional dosing strategies were explored. At this time, a new long-acting injectable formulation of aripiprazole, aripiprazole lauroxil, was considered due higher dosing options (aripiprazole lauroxil $882 \mathrm{mg}$ every 4weeks, equivalent to aripiprazole LAI $600 \mathrm{mg}$ ) $[8,13]$. Therefore, in December 2015, the decision was made to switch to aripiprazole lauroxil $882 \mathrm{mg}$ IM (gluteal) every 4-weeks. Although the plan was to continue the oral aripiprazole for 3 weeks, the patient discontinued the oral aripiprazole on his own after the first injection. The patient initially noted injection site pain with the lauroxil formulation after the first 2 administrations, but no other adverse reactions were reported. Due to the every 3-weeks (aripiprazole LAI) vs. every 4-weeks (aripiprazole lauroxil) dosing strategies, the approximate daily doses from two long acting formulations were similar $(19 \mathrm{mg} /$ day with aripiprazole LAI vs. $21 \mathrm{mg} /$ day with aripiprazole lauroxil, respectively). As of February 2017, he continues to tolerate the aripiprazole lauroxil and reports not needing to use oral aripiprazole.

Table 2 Patient's pharmacogenetic test results

\begin{tabular}{|c|c|c|}
\hline Gene & Genotype & Predicted Phenotype \\
\hline$\overline{C Y P 2 C 19}$ & $* 1 / * 2$ & Intermediate Metabolizer \\
\hline CYP2D6 & $*^{*} 1 / *^{2}$ & Extensive (Normal) Metabolizer \\
\hline СYР3A4/CYP3A5 & ${ }^{*} 1 /{ }^{*} 1 ;{ }^{*} 1 /{ }^{*} 1$ & Extensive (Normal) Metabolizer \\
\hline UGT2B15 & $*^{*} 1 / *_{1}$ & Extensive (Normal) Metabolizer \\
\hline DRD2 & INS/DEL & Reduced Responder \\
\hline HTR2C & $\mathrm{C} / \mathrm{C}$ & Normal Expressor \\
\hline MTHFR & C/C (C677T); A/A (A1298C) & Normal Activity \\
\hline
\end{tabular}

CYP cytochromes P450, UGT uridine 5'-diphospho-glucuronosyltransferase, DRD2 dopamine receptor D2 gene, HTR2C 5-hydroxytryptamine receptor 2C gene, MTHFR methylene tetrahydrofolate reductase gene 


\section{Discussion}

Here, we report a case of an African American male experiencing breakthrough symptoms towards the end of the LAI cycle at a high dose of aripiprazole LAI, even in combination with additional oral supplementation. This patient benefited from switching to the lauroxil formulation. Pharmacogenetic testing revealed that the patient is a CYP2D6 normal metabolizer but carries a $-141 \mathrm{C}$ Ins/Del polymorphism in DRD2 gene.

In the present case, after multiple antipsychotic failures, aripiprazole therapy has been beneficial in reducing depression, psychotic symptoms, and self-injurious behaviors, but patterns of symptom re-emergence resulted in efforts to determine how best to optimize therapy. Several factors related to AB's increased aripiprazole dose requirements and breakthrough symptoms were assessed, including medication/substance interactions, injection technique (i.e. length and gauge of the needle and site of administration), and pharmacokinetic characteristics (i.e. large volume of distribution and BMI). Although previous studies suggest that sites of injection as well as injection techniques may impact the pharmacokinetics of other LAI antipsychotics [14, 15], we confirmed that aripiprazole LAI was administered according to the FDA labeling recommendations [8] to rule out improper injection technique or location as a source of dosing/administration variability. In addition, no other factors were found to possibly contribute to his patterns of response.

Aripiprazole is primarily metabolized by CYP3A4 and CYP2D6. Diminished CYP2D6 activity due to reduced or non-functional alleles results in an $80 \%$ increase in aripiprazole AUC and 2-fold increase in the elimination half-life in CYP2D6 poor metabolizers (PMs) as compared to extensive metabolizers (EMs), leading to a recommendation to start at a lower dose in CYP2D6 PMs $[8,16]$. CYP2D6 ultra-rapid metabolizers (UMs) have increased activity due to functional allele duplications as compared to those who are EMs, and although it is presumed these patients may experience lower levels of aripiprazole and increased concentrations of the CYP2D6 metabolite dehydroaripiprazole, there is a dearth of literature related to this topic. Initially, we hypothesized that this patient may be an UM for CYP2D6 due to his atypical dose requirements; however, this was ruled out with pharmacogenetic testing.

Interestingly the pharmacogenetic test report noted that the patient carries a polymorphism in the DRD2 gene (-141C Ins/Del, rs1799732). This polymorphism is located in the promoter region of DRD2 and shown to influence D2 expression $[11,12]$. A number of candidate gene studies have investigated the relationship between the $-141 \mathrm{C}$ Ins/Del variant and susceptibility to schizophrenia, producing conflicting results [17, 18]. Other genetic studies have identified over 4000 variants in $D R D 2$, some of which were shown to be related to risk for psychiatric disorders in genome-wide association studies (GWAS) [19]. A meta-analyses of 6 studies identified an association of the $-141 \mathrm{C}$ Del polymorphism with poorer clinical response to antipsychotic agents (risperidone, olanzapine, chlorpromazine, clozapine, and aripiprazole) [6], which resulted in this particular variant being included in some clinically available pharmacogenetic testing panels. When information across all studies is taken into consideration, the composite odds ratio from meta-analysis is 0.65 ( $95 \% \mathrm{CI}=0.43$ to 0.97 ), demonstrating the odds of response to antipsychotics are approximately $35 \%$ less in patients with the 'risk' variant (rs1799732). While research studies suggest that DRD2 genetic variants may contribute to differences in antipsychotic response, the clinical utility of this information is yet unclear.

Our patient's different response to two aripiprazole injection formulations with similar daily doses (from injection: approximately $19 \mathrm{mg} / \mathrm{d}$ vs. $21 \mathrm{mg} / \mathrm{d}$ ) is intriguing. One possible explanation may involve differences in pharmacokinetic profiles between two aripiprazole injection formulations. The pharmacokinetic parameters for these two formulations are included in Table 3. At steady state, decline in drug plasma concentration starts approximately 7 days after injection $\left(\mathrm{T}_{\max }=6.5\right.$ days, see reference [20]) with aripiprazole LAI, whereas the drop is delayed to approximately 21 days after injection $\left(\mathrm{T}_{\max }=21.1\right.$ days $)$ with aripiprazole lauroxil [8]. This is thought to be from more controlled release of the lauroxil formulation after injection via utilization of LinkeRx technology [21, 22]. Given the lack of head to head data,

Table $3 T_{\max }$ and $T_{1 / 2}$ (mean (SD)) of aripiprazole after administration of long acting injectable aripiprazole (Abilify Maintena ${ }^{\oplus}$ ) and aripiprazole lauroxil (Aristada ${ }^{\oplus}$ )

\begin{tabular}{|c|c|c|c|c|}
\hline & \multicolumn{2}{|c|}{ After single gluteal injection of aripiprazole $400 \mathrm{mg}$ equivalents } & \multicolumn{2}{|c|}{ After 4th gluteal injection of aripiprazole $300 \mathrm{mg}$ equivalents ${ }^{\mathrm{a}}$} \\
\hline & Aripiprazole LAI & Aripiprazole lauroxil & Aripiprazole LAl & Aripiprazole lauroxil \\
\hline$T_{\max }($ day) & $22(4-22)^{b}$ & $44.0(11.7)$ & $6.5(0.5-21.2)^{b}$ & 21.1 \\
\hline $\mathrm{T}_{1 / 2}$ (day) & $10.5(3.9)$ & $18.0(4.8)$ & $29.9(8.0)$ & $29(6)$ \\
\hline
\end{tabular}

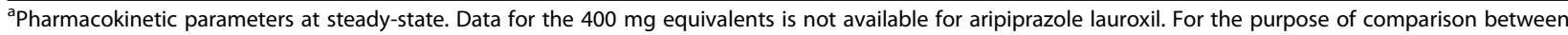
two agents, data for the $\mathbf{3 0 0}$ mg equivalents is included

${ }^{\mathrm{b}}$ Reported as median (range) 
it is difficult to directly compare pharmacokinetics of the two products, although less fluctuation in aripiprazole and its active metabolite levels from slower dissolution rate of aripiprazole lauroxil may explain why our patient does not exhibit wearing-off symptoms anymore with this product.

To date only a few polymorphisms in DRD2 (i.e. rs1800497 and rs1799732) are currently available as clinical tests [5], and even for the variants that are included on commercially available pharmacogenetic panels, literature focusing on how best to use results from those variants (such as an association of the variants with need for altered dosing strategies) is lacking. One recently published study showed that antipsychotic dose requirement is more likely to be increased over time in schizophrenia patients with the $-141 \mathrm{C}$ Del allele compared to the Del non-carriers. Although it was a preliminary study with a relatively small sample size, the findings suggested a relationship between the Del allele and need for higher antipsychotic doses in chronic schizophrenia patients [23]. In addition, the need for altered dosing strategies may be consistent with previous finding indicating that patients with schizophrenia who carry the -141C Del allele had significantly longer time to achieve sustained clinical response to antipsychotic medications compared to those with Ins/Ins homozygous [24]. In this study, authors suggested a possibility that lower brain D2 receptor density in patients having Ins/Ins genotype may make antipsychotic agents more efficient at reaching therapeutic levels of blockade compared to Del carriers.

An additional consideration is that the allele frequencies of variants in DRD2 differ across populations, with the $-141 \mathrm{C}$ Del variant known to be more common in persons of African Ancestry (up to approximately 60\%), such as our patient $[25,26]$. While extensive differences in antipsychotic responsiveness are not usually observed across race groups, one previous study showed that the proportion of patients being prescribed antipsychotic dosages above the recommended range (300-1000 chlorpromazine equivalents) was $10 \%$ higher in African Americans compared to Caucasians ( $p$-value $=0.003$ ). However, the use of depot injections may confound the association between higher antipsychotic dosing and patient race in this study [27]. Two other studies have also reported that African Americans were more likely to be on a high dose (>1000 chlorpromazine equivalents) than Caucasians $[28,29]$, although Segal et al. concluded the results may be due to less treatment engagement with African American patients [29]. As confounding factors (i.e. use of LAI antipsychotics or treatment engagement) made it difficult to accurately assess this relationship, more research is needed to examine how race or ancestry may influence antipsychotic dosing patterns. One hypothesis for further investigation is that higher allele frequency of the $-141 \mathrm{C}$ Del variant in persons of African Ancestry may, at least in part, explain higher antipsychotic doses in these patients.

\section{Conclusions}

We report an African American patient who exhibited wearing-off symptoms with aripiprazole LAI and then benefited from changing to the aripiprazole lauroxil formulation. Pharmacogenetic testing ruled out genetic alteration that may influence drug metabolism, but noted that the patient carries a DRD2 -141C Del polymorphism (rs1799732), which may alter D2 density in the brain. It is important to clarify that co-occurrence of this variant in an individual having a history of antipsychotic nonresponse and increased dosing requirements does not imply causation. However, previous meta-analyses have associated this polymorphism with reduced response, and it is included on some psychiatry focused pharmacogenomic panels for this reason, but without guidance or supporting evidence to suggest what to do for carriers. The importance of presenting this case is therefore two-fold. The first is that some patients with partial response or symptom recurrence towards the end of the usual dosing interval for aripiprazole LAI may benefit from switching to an alternative formulation. The reasons for this are unclear and warrant further investigation. Second, our case suggests that some individuals may be sensitive to the pharmacokinetic differences between the aripiprazole LAI and lauroxil formulations at similar overall exposures, but the biological reasons for this are unknown. One hypothesis for further exploration is that genetic variation resulting in altered D2 expression or function may result in altered sensitivity to antipsychotic medications, requiring different dosing or drug selection strategies.

\section{Abbreviations \\ CYP: Cytochrome P450; DRD2: Dopamine-D2 receptor gene; EM: Extensive metabolizer; FDA: U.S. Food and Drug Administration; GWAS: Genome-wide association studies; IM: Intramuscularly; LAI: Long-acting injectable; PM: Poor metabolizer; UM: Ultra-rapid metabolizer}

\section{Acknowledgements \\ We express gratitude to the patient presented here.}

Funding

There was no funding source.

Availability of data and materials

Data sharing is not applicable to this article, as this is a single-patient case report. No datasets besides those reported in the article were generated during the current study.

Authors' contributions

SE, MES, JTB, AML, and JRB were all involved in the medication therapy management and pharmacogenetic assessment of the patient. SE wrote the first draft of the manuscript. All authors contributed in the preparation of the manuscript and have approved the final version of the manuscript. 


\section{Ethics approval and consent to participate}

Not applicable.

\section{Consent for publication}

Written informed consent for publication of this case report was obtained from the patient. A copy of the signed written consent to publish is available for review by the editor of this journal.

\section{Competing interests}

The authors declare that they have no competing interests.

\section{Publisher's Note}

Springer Nature remains neutral with regard to jurisdictional claims in published maps and institutional affiliations.

\section{Author details}

${ }^{1}$ College of Pharmacy, Department of Experimental and Clinical Pharmacology, University of Minnesota, 308 Harvard St. S.E., Minneapolis, MN 55455, USA. ${ }^{2}$ College of Pharmacy, Department of Pharmacy Practice and Pharmaceutical Sciences, University of Minnesota, 1110 Kirby Dr., Duluth, MN 55812, USA. ${ }^{3}$ College of Pharmacy, Department of Experimental and Clinical Pharmacology and College of Medicine, Department of Psychiatry, University of Minnesota, 308 Harvard St. S.E., Minneapolis, MN 55455, USA.

\section{Received: 10 March 2017 Accepted: 22 June 2017}

Published online: 03 July 2017

\section{References}

1. Hasan A, Falkai P, Wobrock T, Lieberman J, Glenthoj B, Gattaz WF, et al. World Federation of Societies of Biological Psychiatry (WFSBP) Guidelines for Biological Treatment of Schizophrenia, part 1: update 2012 on the acute treatment of schizophrenia and the management of treatment resistance. World J Biol Psychiatry. 2012;13:318-78.

2. U.S. Food and Drug Administration. Table of Pharmacogenomic Biomarkers in Drug Labeling. 2017. http://www.fda.gov/Drugs/ScienceResearch/ ResearchAreas/Pharmacogenetics/ucm083378.htm. Accessed 01 Feb 2017.

3. Drozda K, Müller DJ, Bishop JR. Pharmacogenomic testing for neuropsychiatric drugs: current status of drug labeling, guidelines for using genetic information, and test options. Pharmacotherapy. 2014;34:166-84

4. Clinical Pharmacogenetics Implementation Consortium. CPIC Genes-Drugs Pairs. 2017. https://cpicpgx.org/genes-drugs/ Accessed 1 Feb 2017.

5. Eum S, Lee AM, Bishop JR. Pharmacogenetic tests for antipsychotic medications: clinical implications and considerations. Dialogues Clin Neurosci. 2016;18:323-37

6. Zhang J-P, Lencz T, Malhotra AK. D2 receptor genetic variation and clinical response to antipsychotic drug treatment: a meta-analysis. Am J Psychiatry. 2010;167:763-72

7. Pouget JG, Müller DJ. Pharmacogenetics of antipsychotic treatment in schizophrenia. Methods Mol Biol. 2014;1175:557-87.

8. U.S. Food and Drug Administration. FDA Approved Drug Products. 2017. http://www.accessdata.fda.gov/scripts/cder/drugsatfda/. Accessed 01 Feb 2017.

9. Rohde $M, M$ Rk N, Håkansson $A E$, Jensen $K G$, Pedersen $H$, Dige $T$, et al. Biological conversion of aripiprazole lauroxil - An N-acyloxymethyl aripiprazole prodrug. Results Pharma Sci. 2014:4:19-25.

10. Spanarello S, La Ferla T. The pharmacokinetics of long-acting antipsychotic medications. Curr Clin Pharmacol. 2014;9:310-7.

11. Jönsson EG, Nöthen MM, Grünhage F, Farde L, Nakashima Y, Propping P, et al. Polymorphisms in the dopamine D2 receptor gene and their relationships to striatal dopamine receptor density of healthy volunteers. Mol Psychiatry. 1999:4:290-6.

12. Arinami T, Gao M, Hamaguchi $H$, Toru M. A functional polymorphism in the promoter region of the dopamine D2 receptor gene is associated with schizophrenia. Hum Mol Genet. 1997:6:577-82.

13. Meltzer HY, Risinger R, Nasrallah HA, Du Y, Zummo J, Corey L, et al. A randomized, double-blind, placebo-controlled trial of aripiprazole lauroxil in acute exacerbation of schizophrenia. J Clin Psychiatry. 2015;76:1085-90.

14. Yin J, Collier AC, Barr AM, Honer WG, Procyshyn RM. Paliperidone Palmitate Long-Acting Injectable Given Intramuscularly in the Deltoid Versus the Gluteal Muscle: Are They Therapeutically Equivalent? J Clin Psychopharmacol. 2015;35:447-9.
15. Procyshyn RM, Banasch JL, Barr AM, Honer WG. Breakthrough symptoms after switching long-acting injectable paliperidone palmitate from the gluteal to the deltoid site of administration. J Psychiatry Neurosci. 2016;41:E56-7.

16. Swen JJ, Nijenhuis $M$, de Boer A, Grandia L, Maitland-van der Zee AH, Mulder $\mathrm{H}$, et al. Pharmacogenetics: from bench to byte-an update of guidelines. Clin Pharmacol Ther. 2011;89:662-73.

17. Sáiz PA, García-Portilla MP, Arango C, Morales B, Arias B, Corcoran P, et al. Genetic polymorphisms in the dopamine-2 receptor (DRD2), dopamine-3 receptor (DRD3), and dopamine transporter (SLC6A3) genes in schizophrenia: Data from an association study. Prog NeuroPsychopharmacol Biol Psychiatry. 2010;34:26-31.

18. Xiao L, Shen T, Peng D-H, Shu C, Jiang K, Wang G-H. Functional -141C Ins/ Del polymorphism in the dopamine D2 receptor gene promoter and schizophrenia in a Chinese Han population. J Int Med Res. 2013;41:1171-8.

19. Schizophrenia Working Group of the Psychiatric Genomics Consortium. Biological insights from 108 schizophrenia-associated genetic loci. Nature. 2014:511:421-7.

20. Mallikaarjun S, Kane JM, Bricmont P, McQuade R, Carson W, Sanchez R, et al. Pharmacokinetics, tolerability and safety of aripiprazole once-monthly in adult schizophrenia: an open-label, parallel-arm, multiple-dose study. Schizophr Res. 2013;150:281-8.

21. Remenar JF. Making the leap from daily oral dosing to long-acting injectables: lessons from the antipsychotics. Mol Pharm. 2014;11:1739-49.

22. Turncliff R, Hard M, Du Y, Risinger R, Ehrich EW. Relative bioavailability and safety of aripiprazole lauroxil, a novel once-monthly, long-acting injectable atypical antipsychotic, following deltoid and gluteal administration in adult subjects with schizophrenia. Schizophr Res. 2014;159:404-10.

23. Takase M, Kanahara N, Oda Y, Niitsu T, Watanabe H, lyo M. The impacts of dopamine D2 receptor polymorphism and antipsychotic dosage on dopamine supersensitivity psychosis in schizophrenia. Schizophr Res. 2017; doi:10.1016/j.schres.2017.03.014

24. Lencz T, Robinson DG, Xu K, Ekholm J, Sevy S, Gunduz-Bruce H, et al. DRD2 promoter region variation as a predictor of sustained response to antipsychotic medication in first-episode schizophrenia patients. Am J Psychiatry. 2006:163:529-31.

25. Mi H, Thomas PD, Ring HZ, Jiang R, Sangkuhl K, Klein TE, et al. PharmGKB summary: dopamine receptor D2. Pharmacogenet Genomics. 2011;21:350-6.

26. National Center for Biotechnology Information. Database of Single Nucleotide Polymorphisms (dbSNP). 2017. https://www.ncbi.nlm.nih.gov/ projects/SNP/. Accessed 01 Feb 2017

27. Walkup JT, McAlpine DD, Olfson M, Labay LE, Boyer C, Hansell S. Patients with schizophrenia at risk for excessive antipsychotic dosing. J Clin Psychiatry. 2000;61:344-8.

28. Lehman AF, Steinwachs DM. Patterns of usual care for schizophrenia: initial results from the Schizophrenia Patient Outcomes Research Team (PORT) Client Survey. Schizophr Bull. 1998:24:11-20. discussion 20-32

29. Segal SP, Bola JR, Watson MA. Race, quality of care, and antipsychotic prescribing practices in psychiatric emergency services. Psychiatr Serv. 1996:47:282-6.

\section{Submit your next manuscript to BioMed Central and we will help you at every step:}

- We accept pre-submission inquiries

- Our selector tool helps you to find the most relevant journal

- We provide round the clock customer support

- Convenient online submission

- Thorough peer review

- Inclusion in PubMed and all major indexing services

- Maximum visibility for your research

Submit your manuscript at www.biomedcentral.com/submit
C) BioMed Central 